\title{
EL FORO DEL ART. 10 DEL REGLAMENTO 2201/2003: STJUE 24 MARZO 2021, ASUNTO C-603/20 PPU, SS Y MCP
}

\author{
ARTICLE 10 COUNCIL REGULATION 2201/2003: \\ ECJ JUDGEMENT OF 24 MARCH 2021, CASE C-603/20 PPU, \\ SS VMCP
}

\author{
Celia M. Caamiña Domínguez \\ Profesora titular de Derecho internacional privado \\ Universidad Carlos III de Madrid \\ ORCID ID: 0000-0003-1790-9467
}

Recibido: 11.06.2021 / Aceptado: 12.07.2021

DOI: https://doi.org/10.20318/cdt.2021.6281

Resumen: Este trabajo versa sobre la STJUE 24 marzo 2021, asunto C-603/20 PPU, SS v MCP, relativa a la interpretación del art. 10 del Reglamento 2201/2003. El TJUE considera que el art. 10 no resulta de aplicación para determinar la competencia judicial internacional sobre el fondo del asunto, si un menor ha adquirido la residencia habitual en un tercer Estado, tras un traslado o retención ilícitos.

Palabras clave: Reglamento 2201/2003, competencia judicial internacional, sustracción internacional de menores, responsabilidad parental, residencia habitual.

Abstract: This article deals with the Judgment of the Court (Fifth Chamber) of 24 March 2021, Case C-603/20 PPU, SS v MCP, related to the interpretation of Article 10 of Council Regulation (EC) 2201/2003. The Court considers that Article 10 is not applicable to determine jurisdiction if a child has acquired his or her habitual residence in a third State following a wrongful removal or retention in that State.

Keywords: Council Regulation (EC) 2201/2003, jurisdiction, international child abduction, parental responsibility, habitual residence.

Sumario: I. Introducción. II. Hechos del caso. III. Restitución versus responsabilidad parental. IV. Competencia judicial internacional sobre el fondo del asunto en caso de sustracción internacional. 1. Aspectos previos. 2. La génesis del Reglamento 2201/2003. 3. El tenor literal del art. 10 del Reglamento 2201/2003. 4. Regla de competencia especial (art. 10) versus regla de competencia general (art. 8). 5. Interés superior del menor y principio de proximidad. 6. Relación con el Convenio de La Haya de 1980 y el Convenio de La Haya de 1996. V. Conclusiones.

\section{Introducción}

1. El presente trabajo trata sobre la STJUE 24 marzo 2021, asunto C-603/20 PPU, relativa a la competencia judicial internacional en materia de responsabilidad parental ${ }^{1}$.

El asunto se refiere a una menor de nacionalidad británica que fue trasladada por su madre desde el Reino Unido a la India, siendo el padre el que acude a los tribunales británicos para que se pronuncien sobre la responsabilidad parental.

${ }^{1}$ STJUE 24 marzo 2021, asunto C-603/20 PPU, SS y MCP, ECLI:EU:C:2021:231, disponible en https://eur-lex.europa.eu/ legal-content/ES/TXT/?uri=CELEX\%3A62020CJ0603\&qid=1622126647686 
2. Fundamentalmente, se analizará si el art. 10 del Reglamento (CE) núm. 2201/2003 del Consejo, de 27 de noviembre de 2003, relativo a la competencia, el reconocimiento y la ejecución de resoluciones judiciales en materia matrimonial y de responsabilidad parental, por el que se deroga el Reglamento (CE) núm. 1347/2000, resulta o no aplicable en caso de conflicto de competencia entre un Estado miembro y un tercer Estado².

Cabe tener presente que: a) como la demanda fue presentada por el padre ante los tribunales británicos en agosto de 2020, se trata de un asunto que fue planteado ante tribunales de un Estado que todavía aplicaba el Reglamento 2201/2003; b) como la cuestión fue planteada al TJUE en noviembre de 2020, es decir, antes de que finalizase el período transitorio, el TJUE resulta competente para responder a la cuestión ${ }^{3}$.

\section{Hechos del caso}

3. En el año 2017, nació una menor, hija de padre y madre no casados. Los progenitores eran nacionales de la India y tenían permiso de residencia en el Reino Unido, mientras que la menor era de nacionalidad británica ${ }^{4}$.

4. En octubre de 2018, la menor viajó con la madre a la India 5 . Al cabo de unos meses, mientras que la madre regresó al Reino Unido, la menor permaneció en la India con la abuela materna ${ }^{6}$. Según se indica en el relato de los hechos, a partir de entonces la menor únicamente volvió al Reino Unido durante un breve período en abril de $2019^{7}$.

5. En agosto de 2020, el padre solicitó ante los tribunales británicos la restitución de la menor $\mathrm{y}$, por otra parte, que se pronunciaran sobre aspectos relativos al fondo del asunto ${ }^{8}$. La madre impugnó la competencia judicial internacional de los tribunales británicos, considerando que la menor no residía habitualmente en el Reino Unido". Se apunta que los tribunales británicos destacaron "que, aun teniendo plenamente en consideración las alegaciones de la madre, es muy probable que su comportamiento sea constitutivo de un traslado o retención ilícitos de la menor en la India" ${ }^{\prime 10}$.

6. La High Court of Justice (England and Wales), Family Division, planteó al TJUE si resultaba aplicable el art. 10 del Reglamento 2201/2003, teniendo presente que la menor había sido trasladada a un tercer Estado ${ }^{11}$.

${ }^{2}$ DOCE núm. L 338, de 23 diciembre 2003, pp. 1 y ss., modificado por el Reglamento (CE) núm. 2116/2004 del Consejo de 2 diciembre 2004 (DOCE núm. L 367, de 14 diciembre 2004, ELI: http://data.europa.eu/eli/reg/2003/2201/oj). El foro del art. 10 del Reglamento 2201/2003 es una de las reglas que se mantienen, pasando a ser el art. 9, en el Reglamento (UE) 2019/1111 del Consejo, de 25 de junio de 2019, relativo a la competencia, el reconocimiento y la ejecución de resoluciones en materia matrimonial y de responsabilidad parental, y sobre la sustracción internacional de menores, DOUE núm. L 178, de 2 julio 2019, disponible en http://data.europa.eu/eli/reg/2019/1111/oj (vid. E. RodRíGUEZ PINEAU, "El nuevo Reglamento (UE) 2019/1111 en materia matrimonial, responsabilidad parental y sustracción internacional de menores", La Ley Derecho de Familia: Revista jurídica sobre familia y menores, núm. 26, 2020, p. 5.

3 CAG Sr. A. Rantos, 23 febrero 2021, asunto C-603/20 PPU, SS y MCP, ECLI:EU:C:2021:126, disponibles en https:// eur-lex.europa.eu/legal-content/ES/TXT/?uri=CELEX\%3A62020CC0603\&qid=1623074671373, apartado 37.

4 STJUE 24 marzo 2021, asunto C-603/20 PPU, SS y MCP, ECLI:EU:C:2021:231, apartado 19. Con respecto a la relevancia de la nacionalidad de la menor, vid. CAG Sr. A. Rantos, 23 febrero 2021, asunto C-603/20 PPU, SS y MCP, ECLI:EU:C:2021:126, apartados 72 a 78.

5 STJUE 24 marzo 2021, asunto C-603/20 PPU, SS y MCP, ECLI:EU:C:2021:231, apartado 21.

${ }^{6}$ Ibidem, apartados 21 y 22. En las CAG, consta que el regreso se debió a que la normativa india en materia de inmigración no permitía a la menor permanecer allí más de 180 días (CAG Sr. A. RANTOs, 23 febrero 2021, asunto C-603/20 PPU, SS y MCP, ECLI:EU:C:2021:126, apartado 21).

7 STJUE 24 marzo 2021, asunto C-603/20 PPU, SS y MCP, ECLI:EU:C:2021:231, apartado 22.

8 Ibidem, apartado 25.

9 Ibidem, apartado 26.

10 CAG Sr. A. Rantos, 23 febrero 2021, asunto C-603/20 PPU, SS y MCP, ECLI:EU:C:2021:126, apartado 26. Vid. también el apartado 20, en el que se indica que la madre había alegado que tanto ella como la menor habían sido víctimas de violencia ejercida por el padre, y que ya en otra ocasión la madre y la menor se habían trasladado a la India.

11 STJUE 24 marzo 2021, asunto C-603/20 PPU, SS y MCP, ECLI:EU:C:2021:231, apartado 30. 


\section{Restitución versus responsabilidad parental}

7. Cuando un menor es víctima de una sustracción internacional, cabe distinguir entre el mecanismo de restitución y el procedimiento relativo al fondo del asunto ${ }^{12}$.

8. Cabe comenzar señalando que, en materia de sustracción internacional de menores, el Reglamento 2201/2003 contempla una serie de correcciones que operan en el ámbito del procedimiento de restitución del Convenio sobre los aspectos civiles de la sustracción internacional de menores, hecho en La Haya el 25 de octubre de 1980 (en adelante, Convenio de La Haya de 1980) ${ }^{13}$. Estas correcciones se encuentran previstas, fundamentalmente, en el art. 11. Dicho precepto establece que serán de aplicación cuando el titular del derecho de custodia solicite, conforme al Convenio de La Haya de 1980, la restitución de un menor que, teniendo su residencia habitual en un Estado miembro, se encuentra sustraído en otro Estado miembro ${ }^{14}$.

9. Como los Estados miembros del Reglamento emplean el mecanismo de restitución del Convenio de La Haya de 1980 con unas correcciones, es preciso, para activar el art. 11, que el Convenio resulte de aplicación. Para ello, tendrían que darse las siguientes condiciones ${ }^{15}$ :

a) en virtud del art. 4 del Convenio, un "menor" es una persona de edad inferior a dieciséis años;

b) el país de origen del menor -país de su residencia habitual anterior a la sustracción-, y el país requerido -país en el que se encuentra el menor-, han de ser Estados parte del Convenio; y

c) el menor tiene que haber sido trasladado o retenido en el país requerido, con infracción del derecho de custodia atribuido conforme al Derecho vigente en el país de origen (art. 3).

En el caso del mecanismo de restitución, son competentes los tribunales del país requerido, es decir, aquél al que el menor ha sido ilícitamente trasladado o en el que encuentra ilícitamente retenido; ya que en este punto el Reglamento no contempla corrección alguna al Convenio de La Haya de $1980^{16}$. Conforme al art. 16 del Convenio, los tribunales del país requerido han de pronunciarse sobre la restitución, no pudiendo entrar al fondo del asunto hasta que: a) se haya determinado que no procede la restitución del menor; o b) no se haya presentado demanda de restitución en un plazo razonable ${ }^{17}$.

${ }^{12}$ Entre otros, vid. C. AzCÁrRaga Monzonís, "Sustracción internacional de menores. Asunto vinculado con Suiza y España. Comentario de la Sentencia de la Audiencia Provincial de Pontevedra (Sección 1 ${ }^{\text {a }}$ ) núm. 52/2018, de 17 de abril”, Cuadernos de Derecho Transnacional.CDT, vol. 11, núm. 1, 2019, p. 677; A. L. Calvo Caravaca / J. Carrascosa González, "Protección de menores", en A. L. Calvo Caravaca / J. Carrascosa GonzÁlez (dirs.), Tratado de Derecho Internacional Privado, t. II, Valencia, Tirant lo blanch, 2020, pp. 785-786; I. LoRENTE MARTíNEZ, "Sustracción internacional de menores. Especial atención a la aplicación del Convenio de La Haya 25 octubre 1980 y excepción al no retorno inmediato de la menor", Cuadernos de Derecho Transnacional.CDT, vol. 13, núm. 1, 2021, p. 972; I. REIG FABADO, "La construcción del concepto autónomo de residencia habitual del menor en los supuestos de sustracción internacional de menores", Cuadernos de Derecho Transnacional.CDT, vol. 11, núm. 1, 2019, p. 887. Con respecto a la aplicación del Convenio de La Haya de 1980 cuando no se da la circunstancia de que ambos países son Estados miembros, vid., entre otros, C. I. CoRdero Álvarez, "Sustracción internacional de menores extracomunitaria: a vueltas con la obligación de restitución automática del Convenio de la Haya de 1980 en la práctica española", Cuadernos de Derecho Transnacional.CDT, vol. 13, núm. 1, 2021, pp. 134-152.

${ }_{13}$ Ratificado por Instrumento de 28 mayo 1987 (BOE núm. 202, de 24 agosto 1987; rect. BOE núm. 155, de 30 junio 1989; BOE núm. 21, de 24 enero 1996, disponible en https://www.boe.es/buscar/doc.php?id=BOE-A-1987-19691).

${ }^{14}$ Vid., entre otros, I. ReIG FABADO, "La construcción del concepto autónomo de residencia habitual del menor en los supuestos de sustracción internacional de menores”, Cuadernos de Derecho Transnacional.CDT, vol. 11, núm. 1, 2019, pp. 878-879.

${ }^{15}$ Entre otros, vid. C. AzcÁrraga Monzonís, "Sustracción internacional de menores. Asunto vinculado con Suiza y España. Comentario de la Sentencia de la Audiencia Provincial de Pontevedra (Sección $1^{\text {a }}$ ) núm. 52/2018, de 17 de abril”, Cuadernos de Derecho Transnacional.CDT, vol. 11, núm. 1, 2019, pp. 673-674; M. Herranz Ballesteros, "Análisis del consentimiento del progenitor al desplazamiento o la retención del menor en un Estado distinto al de su residencia habitual. su interpretación en el Auto de la Audiencia Provincial Barcelona (sección 18 ${ }^{\mathrm{a}}$ ) de 27 de noviembre", Cuadernos de Derecho Transnacional. CDT, vol. 11, núm. 2, 2019, pp. 643-646; I. LoRENTE MARTínez, "Sustracción internacional de menores. Especial atención a la aplicación del Convenio de La Haya 25 octubre 1980 y excepción al no retorno inmediato de la menor", Cuadernos de Derecho Transnacional.CDT, vol. 13, núm. 1, 2021, p. 969.

${ }^{16} \mathrm{Al}$ respecto, vid. los arts. 11, 12, 13 y 20 del Convenio de La Haya de 1980.

17 A. L. Calvo Caravaca / J. Carrascosa González, "Protección de menores", en A. L. Calvo Caravaca / J. Carrascosa GonzÁLEZ (dirs.), Tratado de Derecho Internacional Privado, t. II, Valencia, Tirant lo blanch, 2020, pp. 785-786. 
10. El caso objeto de análisis versa sobre la competencia judicial internacional de los tribunales británicos, por lo que cabe plantearse si dicha competencia podría referirse al procedimiento de restitución. En el caso, la menor se encuentra en la India, entendiendo el padre que ello se debe a que ha sido víctima de una sustracción internacional. Cabe tener presente que la India no es un Estado parte del Convenio de La Haya de $1980^{18}$. Por ello, no cabría aplicar ni el mecanismo de restitución del Convenio de La Haya de 1980, ni las correcciones que contempla el Reglamento 2201/2003 en su art. 11.

Además, aunque la India fuera un Estado parte del Convenio de La Haya de 1980 y el mecanismo de restitución pudiera ser aplicado, la competencia judicial internacional de los tribunales británicos no podría basarse en dicho Convenio. Ello se debe, como hemos indicado, a que los tribunales competentes para pronunciarse sobre la restitución serían los tribunales del país requerido, es decir, los tribunales de la India.

11. Una vez descartada la posibilidad de que la competencia judicial internacional de los tribunales británicos se refiera al mecanismo de restitución, cabe plantearse si pueden ser competentes para conocer del fondo del asunto.

Entre los foros que al respecto contempla el Reglamento 2201/2003, se encuentra el art. 10, sobre el que versa el pronunciamiento del TJUE.

\section{Competencia judicial internacional sobre el fondo del asunto en caso de sustracción interna- cional}

\section{Aspectos previos}

12. En sus arts. 8 y siguientes, el Reglamento $2201 / 2003$ contempla foros en materia de responsabilidad parental. En virtud de dichos foros, los tribunales pueden pronunciarse sobre los derechos y deberes relativos a la persona y/o los bienes de un menor (art. 2, apartado 7, Reglamento 2201/2003). Es decir, conforme a tales foros, sí cabe entrar al fondo del asunto.

13. Con carácter general, el Reglamento establece que la competencia judicial internacional en materia de responsabilidad parental corresponde a los tribunales del Estado miembro de residencia habitual del menor al tiempo de presentación de la demanda (art. 8.1). No obstante, el art. 8.2 matiza que: "El apartado 1 estará sujeto a lo dispuesto en los artículos 9, 10 y $12 "$.

14. Como se verá, la STJUE versa, fundamentalmente, sobre el art. 10 del Reglamento 2201/2003. Cabe precisar que, como se ha indicado que el art. 8 está sujeto también al art. 12 del Reglamento, y los progenitores de la menor eran una pareja no casada, los tribunales británicos se plantearon la aplicación del art. 12.3 del Reglamento. Dicha opción fue descartada porque uno de los requisitos que establece el precepto es que la "competencia haya sido aceptada expresamente o de cualquier otra forma inequívoca por todas las partes en el procedimiento..." y no existía tal aceptación por parte de la madre ${ }^{19}$.

${ }_{18}$ Vid. el listado de Estados parte, disponible en https://www.hcch.net/es/instruments/conventions/status-table/?cid=24 (fecha de consulta: 7 junio 2021). Con respecto a las consecuencias de que uno de los países no sea parte del Convenio de La Haya de 1980, vid. I. Lorente Martínez, "Competencia judicial internacional de los tribunales españoles en los casos de sustracción de menores. El trato desigual en situaciones similares”, Cuadernos de Derecho Transnacional.CDT, vol. 11, núm. 1, 2019, pp. 825-833.

19 STJUE 24 marzo 2021, asunto C-603/20 PPU, SS y MCP, ECLI:EU:C:2021:231, apartado 27 y 63; CAG Sr. A. RANTOS, 23 febrero 2021, asunto C-603/20 PPU, SS y MCP, ECLI:EU:C:2021:126, apartado 93. La falta de aceptación de la madre impide también aplicar el art. 12.4 del Reglamento, que hace alusión a la residencia habitual en un tercer Estado no parte en el Convenio de La Haya de 1996 (CAG Sr. A. RANTos, 23 febrero 2021, asunto C-603/20 PPU, SS y MCP, ECLI:EU:C:2021:126, apartado 94). Al respecto, vid. Comisión Europea, Guía práctica para la aplicación del Reglamento Bruselas II bis, 2015, p. 33, disponible en https://op.europa.eu/es/publication-detail/-/publication/f7d39509-3f10-4ae2-b993-53ac6b9f93ed (fecha de consulta: 9 junio 2021). 
15. Volviendo al art. 8 del Reglamento $2201 / 2003$, cabe apuntar que fue diseñado, con carácter general, para determinar la competencia judicial internacional en materia de responsabilidad parental ${ }^{20}$. En cambio, el art. 10 está previsto, expresamente, para los casos en que dicha responsabilidad parental se refiere a un menor que ha sido víctima de una sustracción internacional ${ }^{21}$.

16. Para determinar si el art. 10 resulta de aplicación por los tribunales británicos, a pesar de que la menor se encuentra en un tercer Estado, se observa que el TJUE toma en consideración diferentes elementos:

- la génesis del Reglamento 2201/2003,

- el tenor literal del art. 10 del Reglamento 2201/2003,

- la regla de competencia especial del art. 10 versus la regla de competencia general del art. 8 del Reglamento 2201/2003,

- el interés del menor y el principio de proximidad, y

- la relación del Reglamento 2201/2003 con el Convenio de La Haya de 1980 y con el Convenio de La Haya de 19 de octubre de 1996, relativo a la competencia, la ley aplicable, el reconocimiento, la ejecución y la cooperación en materia de responsabilidad parental y de medidas de protección de los niños ${ }^{22}$.

\section{La génesis del Reglamento $2201 / 2003$}

17. Cuando la Unión Europea se planteó la necesidad de elaborar un Reglamento que resultase de aplicación, entre otros aspectos, a la sustracción internacional de menores, señala el TJUE que el objetivo era el de establecer el régimen aplicable "a las sustracciones de menores en el interior de la Unión" ${ }^{23}$. En cambio, las sustracciones en las que no se diese tal circunstancia, seguirían siendo reguladas por Convenios internacionales, como el Convenio de La Haya de 1980 -que ya estaba en vigor antes de que viera la luz el Reglamento 2201/2003-24.

Al respecto, el TJUE recuerda que en el Informe sobre la Propuesta de Reglamento que elaboró la Comisión de Libertades y Derechos de los Ciudadanos, Justicia y Asuntos Interiores, se hacía alusión al futuro Reglamento "como un instrumento que puede proporcionar un sistema más integrado dentro de la Unión Europea y funcionar junto con los Convenios de La Haya de 1980 y 1996 en la esfera internacional" 25 .

Así, por lo que se refiere al Convenio de La Haya de 1980, la doctrina señala que el Reglamento 2201/2003 sigue la tesis de la alteración del Convenio, de tal forma que, si el país de origen y el país requerido son Estados miembros del Reglamento, se aplica el mecanismo de restitución del Convenio de La Haya de 1980, con las correcciones del Reglamento ${ }^{26}$.

${ }^{20}$ CAG Sr. A. Rantos, 23 febrero 2021, asunto C-603/20 PPU, SS y MCP, ECLI:EU:C:2021:126, apartado 45.

${ }^{21}$ Ibidem, apartado 47.

${ }^{22}$ Vid. Instrumento de Ratificación del Convenio relativo a la competencia, la ley aplicable, el reconocimiento, la ejecución y la cooperación en materia de responsabilidad parental y de medidas de protección de los niños, hecho en La Haya el 19 de octubre de 1996, BOE núm. 291, de 2 diciembre 2010, disponible en https://www.boe.es/diario_boe/txt.php?id=BOEA-2010-18510

${ }^{23}$ STJUE 24 marzo 2021, asunto C-603/20 PPU, SS y MCP, ECLI:EU:C:2021:231, apartado 50.

24 Ídem.

${ }^{25}$ Ibidem, apartado 52. Informe sobre la propuesta de Reglamento del Consejo relativo a la competencia, el reconocimiento y la ejecución de resoluciones judiciales en materia matrimonial y de responsabilidad parental derogando el Reglamento (CE) $n^{\circ}$ 1347/2000 y modificando el Reglamento (CE) $n^{\circ}$ 44/2001 en materia de alimentos (COM(2002) 222 - C5-0234/2002 - 2002/0110(CNS)), Final A5-0385/2002, Comisión de Libertades y Derechos de los Ciudadanos, Justicia y Asuntos Interiores, Parlamento Europeo, 7 noviembre 2002, versión en español (p. 20), disponible en https://www.europarl.europa.eu/sides/ getDoc.do?pubRef=-//EP//NONSGML+REPORT+A5-2002-0385+0+DOC+PDF+V0//ES\&language=ES (fecha de consulta: 9 junio 2021).

26 A. L. Calvo Caravaca / J. Carrascosa González, "Protección de menores", en A. L. Calvo Caravaca / J. Carrascosa GonzÁLEZ (dirs.), Tratado de Derecho Internacional Privado, t. II, Valencia, Tirant lo blanch, 2020, pp. 824-825. 
18. Como el Reglamento $2201 / 2003$ fue diseñado, en lo que respecta a la sustracción de menores, para que sus previsiones fueran aplicadas cuando el país de origen y el país requerido fuesen -ambos- Estados miembros; considera el TJUE que no cabe su aplicación al caso objeto de análisis, al ser el país requerido un tercer Estado -India- ${ }^{27}$.

\section{El tenor literal del art. 10 del Reglamento 2201/2003}

19. En el art. 10 del Reglamento 2201/2003, que lleva por título "Competencia en caso de sustracción de menores", cabe distinguir ${ }^{28}$ :

a) Regla general: la competencia judicial internacional en materia de responsabilidad parental, relativa a un menor que ha sido víctima de una sustracción, corresponde a los tribunales del Estado miembro de residencia habitual del menor anterior a la sustracción.

b) Regla excepcional: la competencia judicial internacional corresponderá a los tribunales del Estado miembro de la nueva residencia habitual si se da uno de los siguientes supuestos:

- el titular del derecho de custodia ha dado su conformidad al traslado o retención del menor, o bien

- el menor, que lleva residiendo al menos durante 1 año en el Estado miembro de la sustracción, se encuentra integrado en su nuevo medio y, cumulativamente, se da una de las condiciones de los apartados i a iv) del art. $10^{29}$.

20. El precepto contempla la posibilidad de que la competencia judicial internacional de los tribunales de un Estado miembro -residencia habitual previa a la sustracción- se transfiera a los tribunales de otro Estado miembro -nueva residencia habitual como consecuencia de la sustracción- ${ }^{30}$. Se observa que se emplea el término Estado miembro, y no otras expresiones como Estado o Estado tercero ${ }^{31}$. Así, entiende el TJUE que los criterios del art. 10 del Reglamento 2201/2003 "se refieren a una situación que se circunscribe al territorio de los Estados miembros" ${ }^{\prime 3}$.

No acoge así el TJUE la interpretación propuesta por el Abogado General, que planteaba que, en virtud del art. 10 del Reglamento, la transferencia de competencia se produciría si el menor fuera trasladado o retenido en un Estado miembro ${ }^{33}$. En cambio, si el menor fuera trasladado o retenido en un tercer Estado, sostenía el Abogado General que, al no producirse la mencionada transferencia, el Estado miembro de residencia habitual anterior a la sustracción conservaría su competencia ${ }^{34}$.

21. En el ámbito del art. 10, entiende el TJUE que existe un potencial conflicto de competencia entre tribunales de diferentes Estados miembros ${ }^{35}$. Esta idea ya había sido acogida en su Sentencia de 17 octubre 2018, asunto C-393/18 PPU, UD contra $X B^{36}$.

27 STJUE 24 marzo 2021, asunto C-603/20 PPU, SS y MCP, ECLI:EU:C:2021:231, apartado 50.

28 Sobre los distintos supuestos del art. 10 del Reglamento 2201/2003, vid., entre otros, C. M. CAAmiÑa DomínguEz, La sustracción de menores en la Unión Europea, Madrid, Colex, 2010, pp. 102-112.

${ }_{29}$ El plazo de 1 año se computa desde que el titular del derecho de custodia tuvo o debió haber tenido conocimiento de su paradero (art. 10.b) Reglamento 2201/2003).

30 STJUE 24 marzo 2021, asunto C-603/20 PPU, SS y MCP, ECLI:EU:C:2021:231, apartado 38. Vid., entre otros, E. RoDRÍGUEZ PINEAU, "La oposición al retorno del menor secuestrado: movimientos en Bruselas y La Haya", Revista electrónica de estudios internacionales, núm. 35, 2018, p. 15.

31 STJUE 24 marzo 2021, asunto C-603/20 PPU, SS y MCP, ECLI:EU:C:2021:231, apartado 40.

32 Ibidem, apartado 39.

33 CAG Sr. A. Rantos, 23 febrero 2021, asunto C-603/20 PPU, SS y MCP, ECLI:EU:C:2021:126, apartados 53 a 56.

34 Ídem.

35 STJUE 24 marzo 2021, asunto C-603/20 PPU, SS y MCP, ECLI:EU:C:2021:231, apartado 41.

36 STJUE 17 octubre 2018, asunto C-393/18 PPU, UD contra XB, ECLI:EU:C:2018:835, disponible en https://eur-lex. europa.eu/legal-content/ES/TXT/?uri=CELEX\%3A62018CJ0393\&qid=1622472470300 
En dicho asunto, relativo a una menor nacida en Bangladés, que nunca había estado presente en territorio británico, se consultó si la presencia física de un menor en un Estado miembro era un elemento esencial de la residencia habitual, a los efectos del art. 8.1 del Reglamento 2201/2003 ${ }^{37}$. Al respecto, se señaló que el art. 8 del Reglamento 2201/2003 no requería que se vieran implicados varios Estados miembros, sino que "a diferencia de algunas disposiciones del Reglamento (...) — como son sus artículos 9,10 y $15-$ - cuyos términos implican necesariamente que su aplicación depende de la existencia de un potencial conflicto de competencia entre órganos jurisdiccionales pertenecientes a varios Estados miembros, del tenor del artículo 8, apartado 1, de dicho Reglamento no se desprende que esa disposición se limite a litigios relativos a tales conflictos" ${ }^{\prime 3}$.

Así, se reitera, como había indicado el TJUE, la necesidad de un potencial conflicto de competencia entre tribunales de Estados miembros, para la aplicación del art. 10 del Reglamento ${ }^{39}$. Por lo tanto, entiende el TJUE que el art. 10 no puede ser empleado para resolver un conflicto de competencia entre un Estado miembro y un tercer Estado ${ }^{40}$.

\section{Regla de competencia especial (art. 10) versus regla de competencia general (art. 8)}

22. Como se ha adelantado, el foro general que el Reglamento 2201/2003 contempla en materia de responsabilidad parental, es el del Estado miembro de residencia habitual del menor al tiempo de la presentación de la demanda (art. 8.1). Entre las excepciones, se encuentra el art. 10 de dicho Reglamento.

$\mathrm{Si}$, en materia de responsabilidad parental de un menor que ha sido víctima de una sustracción internacional se aplicase, con carácter general, la regla del art. 8.1, ello permitiría que el sustractor acabase provocando la competencia judicial internacional del Estado miembro de la sustracción. Por ello, únicamente si se dan las circunstancias del art. 10 -apartados a) o b)-, la competencia judicial internacional se transferirá a los tribunales del Estado miembro de la sustracción ${ }^{41}$.

Como la menor del caso objeto de análisis se encuentra residiendo en un tercer Estado -India-, no cabría aplicar el art. 8.1 del Reglamento, al no residir habitualmente en un Estado miembro ${ }^{42}$. Al no darse el supuesto del foro general (art. 8.1), la regla especial del art. 10 que, dependiendo de las condiciones, permitiría conservar la competencia, tampoco resulta aplicable ${ }^{43}$.

23. Al ser el art. 10 del Reglamento 2201/2003 una regla especial, el TJUE añade que ha de ser objeto de una interpretación estricta, no pudiendo ser interpretado atendiendo a una sola parte de su redacción ${ }^{44}$. Así no cabe admitir que el inicio del precepto "En caso de traslado o retención ilícitos de un menor, los órganos jurisdiccionales del Estado miembro en el que residía habitualmente el menor inmediatamente antes del traslado o retención ilícitos conservarán su competencia..." no va unido a la segunda parte “... hasta que el menor haya adquirido una residencia habitual en otro Estado miembro... "45. Es decir, no cabe sostener que la primera parte del precepto permita conservar de manera indefinida su competencia al Estado miembro de la residencia habitual anterior a la sustracción, cuando el país de la sustracción es un tercer Estado ${ }^{46}$.

\footnotetext{
37 Ibidem, apartado 16.

38 Ibidem, apartados 32 y 33.

39 STJUE 24 marzo 2021, asunto C-603/20 PPU, SS y MCP, ECLI:EU:C:2021:231, apartado 41.

40 Ídem.

${ }^{41}$ Ibidem, apartado 45.

42 Ibidem, apartado 46.

43 Ídem.

${ }^{44}$ Ibidem, apartado 47.

45 Ibidem, apartado 48.

46 Ibidem, apartados 46 y 48.
} 


\section{Interés superior del menor y principio de proximidad}

24. Añade el TJUE que, si el Estado miembro de residencia habitual anterior a la sustracción pudiera conservar su competencia de manera indefinida, ello no respondería al interés superior del menor, al no darse preferencia al criterio de proximidad ${ }^{47}$. Al respecto, recordando el asunto Povse, el TJUE pone de manifiesto la necesidad de encontrar un equilibrio entre el objetivo de evitar que quien sustrae al menor logre una ventaja derivada de la sustracción que ha llevado a cabo, y la conveniencia de respetar el criterio de proximidad ${ }^{48}$.

Así, si el tribunal del Estado miembro de origen pudiera conservar su competencia sin que fueran tomadas en consideración las características de la situación del concreto menor, podría impedir que se declarase competente el tribunal que resultase "más idóneo" 49 . Se indica que esta idea también se recoge en el art. 16 del Convenio de La Haya de $1980^{50}$. Como hemos señalado con anterioridad, el Convenio contempla que ello puede ocurrir cuando se haya determinado que no procede la restitución del menor; o cuando no se haya presentado demanda de restitución en un plazo razonable.

25. En cambio, el Abogado General recuerda que la regla general es que, en caso de sustracción ilícita de un menor, los tribunales del Estado miembro de origen han de conservar su competencia, para evitar así que una acción ilegal pueda provocar un cambio de competencia ${ }^{51}$. Entiende así que, si uno de los objetivos del Reglamento es disuadir de las sustracciones de menores, no debería basta la sustracción en un tercer Estado para dejar de aplicar el art. 10 y para que el menor quede privado de los derechos que le confiere el Reglamento ${ }^{52}$.

\section{Relación con el Convenio de La Haya de 1980 y el Convenio de La Haya de 1996}

26. El TJUE también plantea las consecuencias que la interpretación del art. 10 del Reglamento 2201/2003 puede tener sobre otros Convenios internacionales, como el Convenio de La Haya de 1996 y el Convenio de La Haya de 1980.

27. El Convenio de La Haya de 1996 resulta aplicable a las medidas de protección y a la responsabilidad parental de las personas de edad inferior a 18 años. Por lo que respecta al caso objeto de análisis, resulta especialmente relevante su art. 7, en el que se contempla un foro en materia de medidas de protección, para el caso de menores que han sido víctimas de una sustracción internacional.

El art. 10 del Reglamento 2201/2003 y el art. 7 del Convenio de La Haya de 1996 comparten determinadas características:

— se aplican para determinar la competencia judicial internacional con respecto al fondo del asunto,

- con carácter general, establecen que las autoridades competentes son las del país de residencia habitual del menor anterior a la sustracción,

- con carácter excepcional, contemplan una serie de supuestos en los que la competencia judicial internacional será asumida por las autoridades de la residencia habitual posterior a la sustracción,

- el primero de los supuestos consiste en el consentimiento del titular del derecho de custodia al traslado o retención,

\footnotetext{
47 Ibidem, apartado 58.

48 Ibidem, apartado 59, haciendo referencia a la STJUE 1 julio 2010, asunto C-211/10 PPU, Doris Povse contra Mauro Alpago, ECLI:EU:C:2010:400, disponible en https://eur-lex.europa.eu/legal-content/ES/TXT/?uri=CELEX\%3A62010CJ0211 \&qid=1622714691631

49 Ibidem, apartado 60.

${ }^{50}$ Vid. $\S 9$ del presente trabajo.

${ }^{51}$ CAG Sr. A. RANTos, 23 febrero 2021, asunto C-603/20 PPU, SS y MCP, ECLI:EU:C:2021:126, apartados 67 a 69.

52 Ibidem, apartado 70.
} 
- el segundo de los supuestos exige que el menor lleve residiendo habitualmente 1 año en el país de la sustracción -desde que el titular del derecho de custodia conoció o debió haber conocido el paradero del menor- y se encuentre integrado en el nuevo medio. A ello se añade, en el caso del Convenio de La Haya de 1996 "sin que se encuentre todavía pendiente petición alguna de retorno presentada en este plazo", mientras que en el Reglamento se detallan cuatro supuestos: a) que no se haya presentado una demanda de restitución, b) que se haya desistido de la demanda de restitución, c) que se haya archivado la demanda de restitución, d) que los tribunales del Estado miembro de residencia habitual del menor anterior a la sustracción hayan dictado una resolución sobre el fondo del asunto que no implique la restitución.

28. El TJUE plantea que, si el art. 10 del Reglamento 2201/2003 permitiera, por encontrarse el menor sustraído en un Estado no miembro, conservar con carácter indefinido la competencia judicial internacional a los tribunales del Estado miembro de origen, entonces quedaría excluida cualquier transferencia de competencia en virtud del art. 7 del Convenio de La Haya de $1996^{53}$. Si se bloquease la transferencia de competencia entre tribunales de Estados parte del Convenio de La Haya de 1996, ello supondría una vulneración del art. 52.3 del Convenio de La Haya de 1996: "Los acuerdos a concluir por uno o varios Estados contratantes sobre materias reguladas por el presente Convenio no afectarán a la aplicación de las disposiciones del presente Convenio en las relaciones de estos Estados con los demás Estados contratantes" ${ }^{14}$.

29. Así, cuando sea preciso determinar si ha de conservar la competencia judicial internacional el país de origen o si ha de ser transferida al país en el que el menor reside como consecuencia de la sustracción, el art. 10 del Reglamento únicamente podrá ser aplicado si ambos países son Estados miembros del mismo ${ }^{55}$.

En cambio, si no se cumple que ambos países son Estados miembros del Reglamento, pero sí son ambos Estados parte del Convenio de La Haya de 1996, ha de aplicarse el art. 7 del Convenio de La Haya de $1996^{56}$.

Así, el TJUE determina que "en el caso de que un menor haya sido objeto de sustracción con traslado a un Estado tercero, en el que haya adquirido, como consecuencia de esa sustracción, una residencia habitual, y de que el órgano jurisdiccional de un Estado miembro que conoce de una acción de responsabilidad parental constate que, a falta de acuerdo entre las partes en el procedimiento sobre la competencia, no puede fundar su competencia en el artículo 12 del Reglamento n. ${ }^{\circ}$ 2201/2003 (...) deberá establecer su competencia con fundamento en los convenios internacionales bilaterales o multilaterales eventualmente aplicables o, en ausencia de tales convenios internacionales, en virtud de sus normas nacionales, de conformidad con el artículo 14 del mencionado Reglamento"57.

30. Ahora bien, cabe tener presente que el país en el que se encuentra la menor -India- no es parte del Convenio de La Haya de $1996^{58}$. Así, tal como indica el Abogado General, la no aplicación del art. 10 del Reglamento no queda suplida por el art. 7 del Convenio de La Haya de $1996^{59}$.

Aunque el art. 7.1 del Convenio de La Haya de 1996 determina que “(...) las autoridades del Estado contratante en el que el niño tenía su residencia habitual inmediatamente antes de su desplazamiento o su retención conservan la competencia hasta el momento en que el niño adquiera una residencia

${ }^{53}$ STJUE 24 marzo 2021, asunto C-603/20 PPU, SS y MCP, ECLI:EU:C:2021:231, apartados 55 y 62.

${ }^{54}$ Ibidem, apartado 55 y 56.

55 Ibidem, apartado 57. Sobre el foro equivalente del Reglamento 2019/1111, vid. B. CAMPUZANo Díaz, "El nuevo Reglamento (UE) 2019/1111: análisis de las mejoras en las relaciones con el Convenio de la Haya de 19 de octubre de 1996 sobre responsabilidad parental", Cuadernos de derecho transnacional. CDT, vol. 12, núm. 1, 2020, p. 107.

56 B. Campuzano Díaz, "El nuevo Reglamento (UE) 2019/1111: análisis de las mejoras en las relaciones con el Convenio de la Haya de 19 de octubre de 1996 sobre responsabilidad parental”, Cuadernos de derecho transnacional. CDT, vol. 12, núm. 1, 2020, p. 107.

57 STJUE 24 marzo 2021, asunto C-603/20 PPU, SS y MCP, ECLI:EU:C:2021:231, apartado 63.

58 Vid. el listado en https://www.hcch.net/es/instruments/conventions/status-table/?cid=70 (fecha de consulta: 3 junio 2021 ).

59 CAG Sr. A. Rantos, 23 febrero 2021, asunto C-603/20 PPU, SS y MCP, ECLI:EU:C:2021:126, apartado 85. 
habitual en otro Estado y (...)", cabe entender que este "otro Estado" ha de ser un Estado contratante. Esta idea encuentra respaldo en el art. 7.3, que hace alusión a "las autoridades del Estado contratante al que el niño ha sido desplazado o donde se encuentra retenido...".

31. Considerando que no resulta aplicable el art. 7 del Convenio de La Haya de 1996 y que tampoco existen otros foros en dicho Convenio que, en el caso objeto de análisis, permitan declararse competentes sobre el fondo el asunto a los tribunales británicos ${ }^{60}$; entendemos que en este caso los tribunales del Reino Unido tendrán que determinar su competencia en virtud de otro convenio internacional del que sean parte tanto el Reino Unido como la India y, en defecto del mismo, tendrán que aplicar sus normas de Derecho internacional privado de producción interna ${ }^{61}$.

\section{Conclusiones}

32. En el presente caso se pone de manifiesto la dificultad para determinar la competencia judicial internacional sobre el fondo del asunto, si se considera que un menor que residía habitualmente en un Estado miembro puede haber sido trasladado o retenido ilícitamente en un tercer Estado.

33. Si ambos países fuesen Estados miembros del Reglamento 2201/2003, el art. 10 determinaría si el Estado miembro de origen puede conservar su competencia judicial internacional o si dicha competencia ha de ser transferida al Estado miembro de la sustracción.

Si no fuesen Estados miembros del Reglamento 2201/2003 ambos países, pero sí fuesen Estados parte Convenio de La Haya de 1996, entonces el art. 7 del Convenio sería el que determinaría si procede conservar o transferir la competencia judicial internacional.

Así, cabe entender que operan inter partes tanto el art. 10 del Reglamento 2201/2003 como el art. 7 del Convenio de La Haya de 1996.

34. Ahora bien, de la interpretación del TJUE se desprende que entonces existen situaciones no cubiertas por el art. 10 del Reglamento ni por el art. 7 del Convenio de La Haya de 1996. En tal caso, si no existe otro convenio internacional en vigor entre el país de la sustracción y el Estado miembro de origen, el Estado miembro de origen tendrá que determinar si dispone de competencia judicial internacional en virtud de sus normas de Derecho internacional privado de producción interna, conforme al art. 14 del Reglamento 2201/2003.

Si las normas de competencia judicial internacional de producción interna se basan en foros como el de residencia habitual del menor al tiempo de presentación de la demanda, la acumulación de competencia condicionada a la aceptación de los progenitores, o la presencia del menor; entonces el Estado miembro de origen no podrá entrar a conocer del fondo del asunto. Es decir, en tal caso, una hipotética sustracción internacional en un tercer Estado provocará la pérdida de competencia judicial internacional del Estado miembro de origen.

35. Por todo ello, resulta esencial continuar promoviendo la ratificación de los instrumentos internacionales que permiten proteger a los menores en caso de sustracción internacional, dada la complejidad que revisten los traslados o retenciones en terceros Estados.

\footnotetext{
${ }^{60}$ Los arts. 11 y 12 del Convenio permiten adoptar, respectivamente, medidas de protección en casos de urgencia o medidas provisionales, a las autoridades del Estado contratante en el que se encuentren el menor o sus bienes (sobre estos preceptos, vid., entre otros, A. L. Calvo Caravaca / J. Carrascosa González, "Protección de menores", en A. L. Calvo Caravaca / J. Carrascosa González (dirs.), Tratado de Derecho Internacional Privado, t. II, Valencia, Tirant lo blanch, 2020, pp. 724-725). Ambos preceptos establecen en su apartado tercero que las medidas dejarán de surtir efecto desde que en el Estado contratante se reconozcan las medidas del Estado no contratante de residencia habitual del menor. Dadas las características de ambos preceptos, tampoco por esta vía se lograría que los tribunales británicos pudieran pronunciarse sobre el fondo del asunto.

${ }^{61} \mathrm{Al}$ respecto, el Abogado General apunta que el órgano jurisdiccional remitente señala que las normas nacionales no contemplan foros adicionales (CAG Sr. A. RANTos, 23 febrero 2021, asunto C-603/20 PPU, SS y MCP, ECLI:EU:C:2021:126, apartado 86).
} 